\title{
Relíquias da casa velha: literatura e ditadura militar, 50 anos depois
}

Tânia Pellegrini ${ }^{1}$

Perdoem a cara amarrada, Perdoem a falta de abraço, Perdoem a falta de espaço, Os dias eram assim.

E quando brotarem as flores E quando crescerem as matas E quando colherem os frutos Digam o gosto pra mim.

Ivan Lins e Vítor Martins

\section{Um parâmetro}

Decorridos cinquenta anos do golpe militar de 1964 - já cristalizado como matéria histórica e tema que tem me acompanhado ao longo de décadas -, é possível repensar questões importantes ainda hoje para a crítica cultural e literária. De modo geral, posso afirmar, desde logo, que a ditadura permanece como uma espécie de parâmetro inescapável para a compreensão de tudo o que veio depois, uma espécie de casa velha a que sempre se volta à procura de vestígios, resquícios e pistas talvez ainda reveladoras, apesar dos inúmeros inventários, balanços, mapeamentos e sínteses escritos depois.

Estudando-os, pois já constituem ampla bibliografia, ${ }^{2}$ é possível encontrar uma série de pontos recorrentes, mesmo sendo seus objetivos e pressupostos críticos bastante diversificados. Além de a censura ser um tópico que recebeu muita atenção, sobretudo no que se refere a sua influência em autores e obras, o método usual de dividir longos períodos em décadas é predominante, com qualificativos já sedimentados; desde os "dourados" anos 1960, considerados o ponto inicial do processo, passando pelos "anos de

\footnotetext{
${ }^{1}$ Doutora em teoria e história literária e professora do Departamento de Letras da Universidade Federal de São Carlos (UFSCar), São Carlos, SP, Brasil. Docente permanente do Programa de Pósgraduação em Estudos de Literatura e do Programa de Pós-graduação em Sociologia da mesma universidade. E-mail: tpelleg@uol.com.br

${ }^{2}$ Ver uma relação dos mais citados, certamente incompleta, na bibliografia geral.
} 
chumbo" da década de 70, seguindo pela "década perdida" dos anos 80 e pela do "desencanto" dos anos 90, chega-se ao "século XXI" prematuramente assumido por vários críticos como corte temporal significativo -, em que se antevê um admirável mundo de novas tecnologias e subjetividades encapsuladas em violência e plasma, refletidas nas produções culturais. Em resumo, um longo período de consequências, cujas causas principais teriam forte relação com o tempo da ditadura militar brasileira.

E realmente foi esse o tempo em que se gestaram projetos e situações determinantes para uma espécie de ponto de inflexão no curso e na dinâmica do processo de desenvolvimento cultural do país, que vinha se fazendo em ritmo pausado. Dentre esses arranjos, cabe de fato destacar a ação da censura, pois a truculência de seu aparato, incidindo diretamente sobre a produção simbólica, inspirou um sem-número de investigações posteriores a sua vigência, que procuraram esmiuçar, na filigrana de cada criação artística, suas marcas reais ou imaginárias. O que parece ter ficado um pouco de lado ou, melhor dizendo, o que chamou pouco a atenção dos pesquisadores de literatura foi seu arcabouço institucional, enquanto pedra angular de toda a estruturação do campo cultural no período. Operada com eficiência e agilidade, sobretudo nos anos mais duros do regime, a censura forneceu a camuflagem necessária para a firme ancoragem de um novo modo de produção cultural no Brasil, interligado ao que se passava internacionalmente, sendo que, no nível da criação, com o amparo de políticas recém-criadas, incentivou direta ou indiretamente uma série de soluções temáticas e formais novas ou mesmo antigas, então revisitadas, em todas as áreas culturais.

Nesse sentido é que este ensaio - amparado em consulta a jornais e revistas de várias décadas, além de revisitar parte da produção crítica sobre o tema e de retomar também minhas próprias pesquisas anteriores $^{3}$ - procura traçar uma visão geral das relações entre as ações específicas do regime militar para o campo cultural com modificações significativas nas matrizes preexistentes na prosa de ficção, sobretudo temáticas, que foram traduzindo o mal-estar e a perplexidade geradas naqueles anos difíceis, bem como suas derivações até os dias de hoje.

\footnotetext{
${ }^{3}$ Refiro-me aos meus livros Gavetas vazias: ficção e política nos anos 70 (1996) e A imagem e a letra: aspectos da ficção brasileira contemporânea (1999) e a alguns escritos esparsos.
} 


\section{Tempos difíceis}

Tomando, então, a censura como ponto inicial, pode-se dizer que, de modo geral, a visão mais linear a seu respeito tende a fixar os anos 1970, os "anos de chumbo", como aqueles em que ela atuou com maior peso, determinando uma espécie de estética do reflexo, na medida em que efetivamente impôs seus "padrões de criação", como se sabe, cortando, apagando, proibindo ou engavetando incontáveis peças, filmes, canções, novelas de TV, artigos de jornal e obras literárias. Por essa lente, toda a produção que conseguiu vir à luz já conteria, refletida em sua forma, elementos que visavam burlar a percepção do censor, numa espécie de código cifrado que só aos iniciados seria dado deslindar.

Mesmo sob censura, porém, entre as famosas receitas culinárias truncadas, figuras e símbolos, poemas variados e os versos d'Os lusíadas, que enchiam as páginas proibidas, muitos jornais e revistas de grande circulação na época, termômetros sensíveis das mudanças culturais, bem como artigos e ensaios acadêmicos, consagraram as expressões hoje emblemáticas "vazio cultural" e "geleia geral", indicando um ácido pessimismo: nada se estava produzindo ou não correspondia mais a padrões reconhecíveis aquilo que se produzia. Apostava-se, inclusive, que, no fim desse tempo tão duro, tanto as gavetas dos criadores quanto as dos censores estariam irremediavelmente vazias. Ledo engano, pois a grande produção desses anos, como se viu depois, traz marcas e cicatrizes, sobre as quais foi possível refletir.

Nos jornais alternativos de então, os "nanicos", como eram chamados, tais como Opinião, Movimento, Verso, Em tempo, Pasquim e outros - que conseguiam juntos, só com venda em bancas, uma circulação superior a das revistas Veja e Manchete -, abrigava-se a produção mais crítica, com nomes respeitáveis de todas as áreas culturais. Por exemplo, Otto Maria Carpeaux, num breve balanço sobre a produção cultural de 1972, "Arte e sobrevivência", para Opinião, escreveu:

Os descontentes com esse estado de coisas costumam denunciar um grande responsável: a censura. Certamente a censura não é a amiga desinteressada da literatura, das artes, do teatro, do cinema; e tem aversão marcada contra as ciências sociais. Mas muito mais forte que a censura afigura-se-me a autocensura. E a autocensura sempre se inspira no medo da censura. Seu motivo 
principal é o instinto de autoconservação econômica, que desaconselha os conflitos, preferindo às artes e às ciências conflitantes, o comodismo e a apatia (Carpeaux, 1973, p. 6).

Visto de hoje, já com distanciamento maior (talvez sempre não de todo suficiente), sabe-se que o centro do problema não é exatamente esse, que existem aí mais nuances e matizes, envolvendo questões estruturais ligadas ao projeto econômico e político do regime e evidenciando um planejamento estratégico específico para a área cultural, encarada então como elemento catalisador para os objetivos de modernização, integração e segurança nacional do país, além de sua inserção no ritmo do capitalismo internacional. Por conseguinte, pensar que a institucionalização da censura foi o único fator a incidir sobre a produção cultural é olhar para um lado da questão, é girar o eixo interpretativo para um lado só, ou, dito de outro modo, é tomar a parte pelo todo.

No meu modo de entender, um dos aspectos mais importantes para uma visão ampliada do fenômeno - deixando de lado análises tópicas de autores e obras, pois não é disso que se trata aqui - refere-se à consolidação dos esquemas mercantis de produção cultural e literária, ou seja, à consolidação de uma indústria cultural brasileira, que se efetivou à sombra da censura. Assim, parece claro que reduzir as características dos produtos dessa indústria, durante a ditadura, apenas à influência de uma censura que se queria contornar, é deixar de lado o formidável processo de gradativa e inexorável transformação nos modos de produção cultural como determinante das novas tendências que se gestavam, e que podem ficar mais claras com um exame das ações governamentais nesse âmbito. Evidentemente, essa determinação não foi uma rua de mão única, pois todo processo desse tipo comporta tensões inescapáveis, uma vez que envolve diferentes instâncias e mediações de criação, produção, veiculação e consumo.

O planejamento da cultura, entendido nesses termos, pode ser demonstrado a partir da criação do Conselho Federal de Cultura, já em 1966, e da análise dos documentos ali produzidos, que visavam estabelecer as bases de uma Política Nacional de Cultura, criando órgãos governamentais com essa finalidade. No entanto, as ações governamentais não constituíram uma política homogênea nem linear, estando permeadas de ambiguidades e contradições. Os trabalhos do Conselho Federal de Cultura demoraram bastante e, em 1973, foi promulgado o documento Diretrizes para uma Política Nacional de Cultura, 
seguido de outro, a Política Nacional de Cultura, em 1975. Enquanto esses documentos eram elaborados, o governo ocupava-se com procurar neutralizar, usando censura e repressão, a produção cultural da esquerda, barulhenta e ativa, o que levou Roberto Schwarz a escrever que o país "estava irreconhecivelmente inteligente" (Schwarz, 1978, p. 61), expressão que frequenta quase todos os textos críticos referentes ao período.

Essa "inteligência" insuflava, então, uma generosa ebulição dos processos criativos, de sentido amplo e de alta voltagem ideológica, pelo menos até a promulgação do Ato Institucional no 5, em 1968. Até então, literatura, teatro, música, cinema e educação buscavam "conscientizar o povo", estabelecendo um circuito coletivo de comunicação e de troca de experiências que, se por um lado acreditava serem os intelectuais e artistas os faróis do povo, por outro, a despeito disso, estabelecia mediações e constituía uma promessa de socialização da cultura e de modernização em termos democráticos (Galvão, 1999). Com relação a esse panorama, Marcelo Ridenti argumenta:

Vislumbrava-se uma alternativa de modernização que não implicasse a submissão ao fetichismo da mercadoria e do dinheiro, gerador de desumanização. A questão da identidade nacional e política do povo brasileiro estava recolocada: buscavase ao mesmo tempo recuperar suas raízes e romper com o subdesenvolvimento, o que não deixa de ser um desdobramento à esquerda da chamada era Vargas, propositora do desenvolvimento nacional com base na intervenção do Estado (Ridenti, 2010, p. 88, grifo meu).

Como eu disse, já são relíquias de uma casa velha, porém, de acordo com meu foco de interesse, é importante retomá-las e destacar que, depois do AI-5, "legalizando" a censura, a primeira metade da década de 1970 foi marcada por um esforço explícito do governo ${ }^{4}$ para neutralizar a produção cultural de esquerda, com vistas a assumir definitivamente o processo cultural, em uma etapa subsequente.

É nesse contexto que a intervenção do Estado evidenciou, sobretudo por meio da Política Nacional de Cultura, de 1975, em primeiro lugar, uma disposição de subsidiar atividades culturais que vinham

\footnotetext{
${ }^{4}$ O Decreto-Lei, de 26 de janeiro de 1970, do Presidente Emilio G. Medici, dispõe, no seu artigo $1^{\text {o: }}$ : "Não serão toleradas as publicações e exteriorizações contrárias à moral e aos bons costumes, quaisquer que sejam os meios de comunicação” (Reimão, 2011, p. 124).
} 
encontrando dificuldades crescentes de sobrevivência em função de critérios estritos do mercado, principalmente a conservação do patrimônio histórico e artístico nacional, já catalogado como museológico e cheio de simbologia, ou atividades eruditas como ópera, balé, música clássica etc.. Atividades, por assim dizer, "neutras" e de ínfima penetração popular, pois, de acordo com Sergio Micelli, "o patrimônio constitui, [portanto], o repositório de obras do passado sobre cujo interesse histórico, documental e por vezes estético, não paira qualquer dúvida. Trata-se de obras e monumentos que, no mais das vezes, já se encontram dissociados das experiências e interesses sociais que lhes deram origem" (Micelli, 1984a, p. 28).

Em segundo lugar, como sublinha o mesmo Micelli, em outro artigo, o governo deixava a cargo da empresa privada as melhores oportunidades de investimento e faturamento no campo da produção cultural mais dinâmica:

Parece haver, assim, uma segmentação irreversível do mercado de bens culturais. Cabe aos grandes empreendedores particulares explorar as oportunidades de investimento naquelas atividades e frentes de expansão capazes de assegurar as mais elevadas taxas de retorno sobre o capital, tais como os fascículos, a televisão, as estações de rádio FM, discos, as fitas cassete ou o videocassete, destinado aos modernos meios de reprodução eletrônica (Micelli, 1984a, p. 26).

Combinam-se, por conseguinte, fatores diversos, e, nos dois documentos governamentais acima citados, Natália Morato Fernandes sublinha o claro objetivo de desbaratar a cultura de oposição:

O documento de 1973 parte da caracterização ampla de cultura e busca articular participação e desenvolvimento. [...] Dá, portanto, certa ênfase ao caráter espontâneo do processo cultural, do qual deveria participar o cidadão comum. [...] a ênfase no cidadão comum, que é apresentada como componente antielitista, tem, na verdade, "a função de tornar dispensáveis as elites indesejáveis" que se identificariam com os segmentos sociais adversos ao regime (Fernandes, 2013, p. 181).

É importante frisar que Fernandes utiliza análises já elaboradas por Gabriel Cohn e é ele quem, referindo-se à Politica Nacional de Cultura, destaca a combinação entre uma concepção essencialista e uma concepção instrumental da cultura, pois já não se invocam mais as 
exigências de segurança e fortalecimento nacionais, a essência do regime; afirma-se agora que o desenvolvimento brasileiro não é apenas econômico, mas social, sendo que dentro dele "há um lugar de destaque para a cultura" como instrumento político-social. Propõem-se, assim, o incremento da participação no processo cultural, o incentivo à produção e a generalização do consumo: "Caberia ao Estado criar os mecanismos necessários para assegurar o acesso de todos ao 'consumo' de bens culturais, estimulando assim a consolidação do mercado para tais produtos" (Cohn, 1984, p. 88).

A Política Nacional de Cultura expressa o clima da "abertura lenta, gradual e segura" iniciada no governo Geisel, não só pelo que significa para a área cultural especificamente mas porque a insere no âmbito maior das estratégias de Estado, considerando-a também como um produto com valor estabelecido até no mercado internacional, o que, para o Brasil da época, ainda não era algo que se levasse tão a sério, devido ao viés nacionalista dominante. Ou seja, passa-se então a considerar a "brasilidade cultural" como um produto de exportação já bem mais elaborado e rentável do que as bananas de Carmem Miranda.

Sempre à sombra da censura, que só foi extinta em 1979, com o fim do AI-5, ${ }^{5}$ criaram-se diversos órgãos de estímulo e ao mesmo tempo de controle, tais como o Concine (Conselho Nacional de Cinema), em 1976, e a Funarte (Fundação Nacional de Arte), em 1975, reformulando-se outros, como a Embrafilme (Empresa Brasileira de Filmes), que fora fundada em 1969. Articulam-se, portanto, nesses documentos, metas muito claras de consolidação da indústria cultural no Brasil, que já existia de forma incipiente, com muito de artesanal e voluntário, desde décadas anteriores (lembre-se, por exemplo, da "era do rádio"), e cuja importância política, institucional e econômica, nesse momento, é estratégica para o projeto modernizador do regime.

Com relação à literatura ou, mais propriamente, ao mercado editorial, destaca-se a iniciativa do Instituto Nacional do Livro (criado em 1937, no governo Vargas), de fomentar durante a ditadura militar uma política de subsídios, iniciando o financiamento de parte das tiragens de livros técnicos, didáticos e paradidáticos, o que gerou um aumento palpável da produção. Essa política de subsídios, além de se

\footnotetext{
${ }^{5}$ Emenda Constitucional no ${ }^{\circ}$ 11, de 13 de outubro de 1978, revogando o Ato a partir de $1^{\underline{0}}$ de janeiro de 1979.
} 
dirigir majoritariamente para as editoras de livros didáticos, estendeuse para editoras de outro tipo, com o apoio a traduções de livros estrangeiros e a publicações de diversos livros de ficção, inclusive por meio de coedições e de subsídios para a implementação de um parque gráfico moderno (Calabre, 2005).

Sergio Micelli enfatiza que, no todo, "foi a única vez na história republicana que o governo formalizou um conjunto de diretrizes para orientar suas atividades na área cultural, prevendo ainda modalidades de colaboração entre os órgãos federais e de outros ministérios [...]" (Micelli, 1984b, p. 57).

Artistas e intelectuais de todas as áreas percebem com clareza os rumos do processo então instaurado. Em um debate organizado pelo alternativo Opinião, "Dez anos de cinema nacional", do qual participaram vários cineastas, dois anos antes da emissão da Política Nacional de Cultura, portanto, Zelito Viana já comenta com objetividade:

No Brasil cresce cada vez mais a dependência de qualquer atividade econômica em relação ao Estado. E o cinema também é uma atividade econômica. O Estado interfere cada vez mais fortemente tanto nas empresas privadas que fazem cinema quanto premiando, financiando e orientando a atividade de qualquer um. Essa influência cresceu sobretudo a partir de 1967, quanto o INC [Instituto Nacional do Cinema] foi criado. [...] Por outro lado, atravessamos hoje no Brasil uma fase industrial muito desenvolvida, fato que vai se refletir no campo do cinema. [...] A capitalização intensiva e extensiva que daí deriva, com novos critérios seletivos, vai funcionar também como um poderoso fator que redefine as condições e as possibilidades do nosso cinema (Viana, 1973, p. 7).

\section{Tempos ambíguos}

No quadro acima delineado, é importante levar em conta que o processo de organização e controle da cultura, estabelecido nos documentos de 1973 e 1975, 6 coincidiu com a elevação do padrão de vida das camadas médias da população, que aos poucos vinha se constituindo como um público novo e ampliado para os modernos bens

\footnotetext{
${ }^{6}$ Uma análise mais detida desses documentos, que não é nosso objetivo aqui, pode levantar ainda muitas outras interpretações importantes para o processo de industrialização da cultura no Brasil de então.
} 
culturais, sobretudo os ligados à comunicação, acentuando-se seu crescimento a partir do "milagre econômico", do início dos anos 1970. Nesse contexto, portanto, a censura funcionou claramente como uma espécie de expressão ideológica do tipo de orientação que o Estado pretendia imprimir à cultura, num momento de descenso forçado da produção engajada e participante dos anos 1960, tornando evidente o esforço do regime para assumir tal espaço, como uma das táticas da estratégia maior de derrotar a esquerda, legitimar-se perante a opinião pública e modernizar o país. Fernandes também considera esse ponto:

Assim, mesmo quando esteve preocupado com a criação de órgãos e instituições culturais oficiais, responsáveis pela implementação de uma Política Nacional de Cultura - pautados pelo referencial da tradição e com o objetivo de proteger e ao mesmo tempo incentivar a cultura e a identidade nacionais - os governos militares estavam dando as condições para a consolidação da indústria cultural no país (Fernandes, 2013, p. 188, grifo meu).

Empenhado em fragilizar a produção cultural de esquerda do período anterior, como destaquei, o Estado firmou sua política específica, calcada na ideologia de integração e de segurança nacionais. Estabeleceu-se, dessa forma, uma contradição aparente. Enquanto criava órgãos estatais de estímulo à cultura e investia em infraestrutura por meio de empréstimos e subvenções (por exemplo, para a modernização das gráficas, editoras, emissoras de rádio e TV, além de crédito para aquisição popular de aparelhos), reforçando a necessidade de organização em moldes empresariais, em que a profissionalização e o mercado eram os pontos cruciais, o Estado controlava com a censura, atendendo assim tanto aos seus próprios interesses quanto aos da indústria cultural em expansão. Na verdade, a contradição não existe. Trata-se de uma chave que gira para os dois lados: ambiguamente impede um tipo de orientação, a de conteúdo ideológico de esquerda, promovendo uma espécie de "higienização", que interessava à ideologia da segurança nacional, mas incentiva outro, aquele que prega Pátria, Deus, moral e bons costumes.

É necessário lembrar que a ideologia de Segurança Nacional constituiu a base do pensamento da ditadura militar em relação à sociedade, concebendo o Estado como uma entidade política que detinha o monopólio da faculdade de coagir, ou seja, de impor até pela força as normas a serem obedecidas, para ser percebido como o centro de todas as 
atividades sociais relevantes; daí a preocupação com a integração, fundamentada em uma instância que pudesse integrar, a partir de um centro, diversidades e divergências. Nesse sentido, a cultura tornara-se efetivamente preocupação estratégica e questão de poder, tanto por sua força simbólica quanto pelo potencial econômico: "integrar para não entregar" foi um dos lemas importantes do regime. Nesse sentido, é precisa a observação de Renato Ortiz:

Não se pode esquecer que a noção de integração estabelece uma ponte entre os interesses dos empresários e dos militares, muito embora ela seja interpretada pelos industriais em termos diferenciados. Ambos os setores veem vantagens em integrar o território nacional, mas enquanto os militares propõem a unificação política das consciências, os empresários sublinham o lado da integração do mercado (Ortiz, 1988, p. 118).

Em resumo: criações específicas em todas as áreas foram censuradas, fortalecendo-se o controle estatal sobre produção e circulação de bens culturais, mas sua produção geral cresceu e firmou-se, amparada pelo "projeto modernizador" do governo militar, que envolveu a consolidação de um setor industrial moderno no país, de fato iniciado em décadas anteriores, incluindo agora a crescente penetração, em nossa economia, de capitais externos associados às empresas nacionais, inclusive as que produziam cultura. Mas os investimentos maiores, no período em questão, ficaram a cargo do Estado, sendo que, depois de consolidados, os empreendimentos passaram para o setor privado ou seu controle foi assumido por grupos particulares, como concessão pública. Segundo Micelli:

Os projetos em pauta teriam contribuído para ampliar a presença governamental justamente naquelas áreas da produção cultural que dispõem de um mercado consumidor em expansão e de cuja rentabilidade comercial dependem as maiores redes privadas de entretenimento e informação atuantes no país (Micelli, 1984b, p. 63).

Dessa maneira, ocorreu muitas vezes um processo duvidoso de "troca de favores", como no caso das estações de rádio e emissoras de televisão, em que uma das moedas de troca era a censura à programação. A propósito, Flora Süssekind destaca três estratégias diferentes na implementação do expansionismo cultural dos governos militares, aglutinadas no que chamo "troca de favores": "o desenvolvimento de uma estética do espetáculo, uma estratégia 
repressiva ladeada pela determinação de uma política nacional de cultura e um hábil jogo de incentivos e cooptações" (Süssekind, 1985, p. 13). Assim, a combinação de censura e cooptação, por meio de estímulos e favores, além da política específica para a cultura, que apontei, estabeleceu um campo de forças muito claro, no interior do qual a "estética do espetáculo" imprimiu sua marca indelével, principalmente pela difusão da imagem televisiva como a maior plataforma de informação e entretenimento do país de então, na "certeza de um controle social efetivo em cada casa que possuísse o seu aparelho transmissor" (Süssekind, 1985, p. 13).

Enfatizo que, até então, a televisão era o veículo cuja relação entre criação e mercantilização fazia-se mais evidente e direta, pelo fato de transmitir ao mesmo tempo publicidade, informação e cultura, para todas as classes sociais. O "espetáculo" - que utilizo nos termos de Guy Debord -7 vai traduzindo assim as transformações econômicas, políticas e sociais do país e conquistando novas faixas de público, pois estas são vitais para a sobrevivência não só da televisão, de implantação ainda recente, como do projeto modernizador do governo e do próprio regime. Nesse aspecto, "integrar" significa, por meio dos estímulos específicos do espetáculo, incorporar setores marginais ao mercado, padronizar aspirações e preferências, diluir ou elidir diferenças, erodir tradições regionais, homogeneizar sonhos e gostos, modernizar hábitos e estabelecer preferências, de acordo com as necessidades criadas pelo próprio mercado de bens materiais e simbólicos. É Arnaldo Jabor quem enfatiza esse ponto, com ironia, comparando televisão e cinema:

O cinema não vai tirar da TV o seu público, que é uma coisa conquistada. A TV é um problema político, não um problema cultural, é um problema de segurança nacional. A TV é a arma mais importante da integração nacional e não estou querendo competir com a TV, que não sou otário (Jabor, 1973, p. 8).

No cerne do "problema político" representado pela TV, não se pode deixar de mencionar, mesmo que rapidamente, a telenovela brasileira, que passa a ser parte intrínseca da estrutura montada, por seu poder de estabelecer interlocuções imaginárias e relevantes com o público, expressas por meio de mecanismos e convenções formais

\footnotetext{
7 “O espetáculo não é um conjunto de imagens, mas uma relação entre pessoas, mediada por imagens” (Debord, 1997, p. 14).
} 
profundamente moldados pela "estética do espetáculo". O risco para o regime era sua capacidade não apenas de representar a realidade, mas de construí-la, em direções muitas vezes imprevistas e não planejadas; e, embora sempre procurando não fugir completamente dos padrões morais, éticos e políticos estabelecidos, sua narrativa, sendo ficcional, poderia suscitar leituras diversificadas, uma vez que toda fiç̧ão tece complexas relações com a subjetividade do receptor. Assim, colocava-se de fato como um problema de segurança nacional e foi um dos produtos culturais mais censurados do período. ${ }^{8}$

O cinema, por sua vez, sempre muito vulnerável aos interesses mercantis, por ser uma atividade que exige grandes investimentos, enfrentou como pôde as questões quase incontornáveis da sua introdução definitiva no esquema industrial. Segundo Fernão Pessoa Ramos,

a questão da introdução no esquema industrial foi, no decorrer dos anos 60/70, o verdadeiro to be or not to be do cinema nacional. O Cinema Novo, por exemplo, debate-se em vão, durante anos, contra a indústria cultural e acaba no final tendo de ceder a seus atrativos. O dilema dos primeiros filmes (como atingir o povo sem passar pela indústria) é substituído pela afirmação de que o mercado (e a distribuição industrial) é um mal necessário (Ramos, 1986, p. 3).

Material e ideologicamente controlados, portanto, os produtos culturais foram acentuando cada vez mais seu caráter de mercadoria, a ponto de ser comum empregar o termo "mecenas" para o Estado, aquele que pagava, mas exigia fidelidade em troca (Holanda e Gonçalves, 1980). É o que enfatiza Millôr Fernandes: “É claro que o governo só financia as obras e os artistas que lhe interessam. Porque os intelectuais que demonstrarem qualquer sinal de rebeldia não serão financiados" (Fernandes, 1983, p. 7).

Em suma, os interesses gerais do Estado e dos novos empresários da cultura tornaram-se os mesmos; a questão da censura foi conjuntural, mas foi à sua sombra e com seu auxílio que se pôde formar e fortalecer um mercado integrado de bens culturais, peça agora importante no processo de internacionalização da economia do país.

Desse modo, é lícito dizer que, no conturbado processo de construção de uma moderna indústria cultural no país, a “estrutura

\footnotetext{
${ }^{8}$ Vale citar como um exemplo Roque Santeiro, de Dias Gomes, censurada no dia de ir ao ar o primeiro capítulo, em 1975. Foi readaptada e veiculada depois, em 1985 e 1986.
} 
profunda" da censura foi mais essencial e atuante que a aparente: enquanto esta se preocupava com cortes e vetos a criações específicas, aquela buscava uma espécie de equalização do controle estatal sobre todo o processo cultural, de maneira a eliminar aos poucos os vestígios de formas de produção artesanais, só possíveis num Brasil "prémoderno", que se queria superar, incompatível com o processo de globalização que já então acelerava os passos.

\section{Novos tempos}

No contexto geral acima descrito, desfaz-se a última ilusão de independência da cultura em relação à economia; até então, vista unicamente como "criação de espírito", em graus diversos nas diferentes áreas, parecera permanecer sempre imune aos avanços do mercado, que lá fora já dava as cartas havia muito tempo. O resultado da política sistemática do regime para a área cultural foi a definitiva impressão do selo do mercado na criação, substituindo o ritmo lento de décadas anteriores, ainda com muito de precário e artesanal, por uma grande pressa produtiva, no atendimento e formação de públicos potenciais. Pode-se afirmar que, desde então, o mercado passou a ser definitivamente um elemento constitutivo da produção cultural, exercendo uma profunda influência, de fora do âmbito artístico, entranhando-se nas configurações de conteúdo e forma.

No que se refere à literatura, como já apontei, o setor livreiro aumentou exponencialmente o número de edições, de títulos e de exemplares publicados, beneficiando-se das políticas de incentivo, que também estimularam a produção de papel e baratearam seu custo, além de subvencionar a importação de máquinas mais modernas. Uma das iniciativas do governo foi a criação da Embralivro, "que tencionava criar dois mil pontos de vendas de livros em todo o território, agilizando a distribuição, desde então diagnosticada como o principal gargalo da indústria editorial" (Micelli, 1984b, p. 63).

Grande parte dos autores nacionais começa a aprender a encaixar sua produção nesses novos parâmetros, por dois motivos: têm que competir num mercado inflado por produtos estrangeiros (cresceu muito o número de best-sellers traduzidos), bem adequados ao gosto do novo público, já formado basicamente pela TV, se possível conseguindo auxílio do Instituto Nacional do Livro para publicação; ao mesmo 
tempo, procuram enganar a censura - os mais progressistas -, para não compactuar com ela. Isso terá uma profunda implicação na forma e no conteúdo dos textos, cuja análise caso a caso já constitui uma ampla e variada fortuna crítica.

A destacar é que, às voltas com a nova situação, adotam-se atitudes e se produzem textos que, grande parte das vezes, foram respostas pessoais inseridas nesse campo de forças exterior ao plano estético, como se viu, com pressões e limites bem determinados. Estes têm a ver com o desenvolvimento específico do mercado livreiro, sempre instável, com altos e baixos sucessivos que também refletem as peculiaridades do leitorado brasileiro, reconhecidamente pouco afeito à leitura, devido a causas conhecidas e discutidas de longa data: ${ }^{9}$ a educação precária, o ensino deficiente, a existência rarefeita de bibliotecas, os baixos salários, o alto preço do livro, a influência da televisão etc.. E o resultado de tudo isso, para a criação literária, segundo o diagnóstico de Lygia Fagundes Telles, no início da "década perdida", é:

O que acontece, atualmente, é que a literatura brasileira está no seu pique, cresceu assustadoramente o número de escritores. Mas a verdade é que a maior parte está em encalhe, são muito ruins. Eu recebo livros muito ruins, já publicados e não os consigo ler. Hoje em dia todo mundo quer escrever. Se o homem está impotente, ele resolve escrever um livro. Se a mulher foi abandonada, ela resolve escrever um livro. É claro que entre os novos tem muita gente de potencial. Apesar de todas as dificuldades, o mercado sempre estará aberto para a boa literatura (Telles, 1981, p. 8).

Concorde-se ou não com a percepção da autora, naquele momento, a reorganização da produção cultural e literária, com todas as implicações nacionais do processo, na verdade também reflete a formidável reorganização da cultura nos países capitalistas em geral, a cujo ritmo o Brasil se ajusta, o que já é discutido por intelectuais e estudiosos. Em um debate sobre identidade cultural, também no Folhetim, em 1981, Roberto Schwarz declara:

De certo modo, estamos assistindo à liquidação da esfera da cultura como ela era definida tradicionalmente em nossa

\footnotetext{
${ }^{9}$ Essas causas atualmente assumem outro peso e outros contornos, devido ao surgimento da internet, o que já demanda critérios de análise adequados à nova situação.
} 
sociedade. Sinais dessa modificação: os assuntos culturais mais discutidos e que chamam mais atenção dos intelectuais são assuntos da esfera dos mass media. [...] Hoje se discute telenovela com a mesma paixão intelectual com que, noutro momento, se discutiriam os romances de Graciliano Ramos. Da mesma forma, aparece no processo a desaparição da fronteira entre os diversos gêneros artísticos [...] o que significa, na verdade, uma ampla reorganização da esfera da cultura no conjunto da civilização capitalista (Schwarz, 1981, p. 6).

Nesse mesmo debate, o poeta Cacaso acrescenta considerações que tangenciam a mesma realidade, mas caminha em sentido oposto:

Atualmente, o mercado é a grande justificativa para a criação brasileira. Eu não vejo mais hoje em dia, na década passada e na que começa agora, não vejo nenhum tipo de ideologia forte motivando a criação. Vejo muito o criador de cultura, o artista diante do mercado. [...] Quer dizer, o fato de você mergulhar no mercado capitalista, a partir de um certo momento, isso é traduzido em liberdade para quem cria, porque você pode ter uma área maior de manobra e de autocontrole da criação, o que vem do fato de você ter remuneração objetiva pelo seu trabalho (Cacaso, 1981, p. 7).

Se Schwarz vê a imersão no mercado como perda, ou melhor, como uma modificação substancial no próprio conceito de cultura, Cacaso analisa-a como ganho objetivo, isto é, como liberdade de criar garantida pelo mesmo mercado, sobretudo porque já não existe mais o forte apelo ideológico que alimentara a criação em décadas anteriores. De qualquer modo, essa interpretação diferente do mesmo fenômeno indica que se coloca uma nova realidade para o setor, aos poucos construída durante o regime militar, e da qual, naquele momento, poucos tinham clareza quanto ao verdadeiro significado. Desde Baudelaire, que perdeu seu "halo" de poeta na rua enlameada, passando por Benjamin, que a retoma como "aura", a discussão desse tema está posta. Menos acalorada atualmente, é necessário dizer, sobretudo porque, terminado o regime militar, o Brasil já estava solidamente instalado no mercado internacional de bens culturais e aos poucos foi se perdendo a hesitação peculiar às avaliações feitas no calor da hora, dando lugar à certeza que o sucesso do projeto, agora realizado, conseguiu estabelecer: criação é produção. Referendando todo o percurso acima descrito, a revista Leia Livros, que circulou de 1978 a 1990, especializada em livros e autores 
(o que também é significativo da saúde do mercado naquele momento), publica no editorial, em 1990:

O fenômeno ainda é localizado e só contempla uma pequena elite. Mas os primeiros passos já foram dados e não resta dúvida de que a profissionalização do escritor é um processo que está em curso. [...] E o mais importante é que não se trata de um fenômeno contingencial, que muda ao sabor dos ventos da economia ou da política nacional. Porque o que parece estar em jogo aqui é uma mudança de mentalidade, a emergência de uma nova e moderna concepção das relações entre autor e editor e a conscientização de que as normas do mercado, que regem outros setores da produção, também devem vigorar no mundo dos livros (Escrever, 1990, p. 3).

Considerando a data dessa assertiva, a última frase é fundamental para entender o alcance do processo efetivado ao longo de 25 anos, desde 1964: as ações empreendidas pelo Estado militarizado, no campo cultural como um todo, conjugadas com as condições internacionais de desenvolvimento do capitalismo, foram fortes o suficiente para conseguir penetrar no coração da instância criativa, consolidando uma mudança de mentalidade - já em gestação anteriormente - também na esfera literária, agora pautada indelevelmente pelas normas do mercado. Pode-se dizer assim que, a partir da ditadura militar, o Brasil ingressou definitivamente na pós-modernidade - aqui entendida como Fredric Jameson a define -, 10 com todas as conhecidas peculiaridades nacionais das transformações ocorridas e que só serão acentuadas a partir de então.

Essas peculiaridades relacionam-se ao fenômeno de aparente aceleração da história global, impulsionado pela proliferação de imagens e simulacros, pela abundância de informações, por uma nova relação com o tempo e o espaço daí decorrentes, com a multiplicação de estímulos e referências reais, imaginárias e simbólicas, com uma espécie de flutuação de percepções e sensibilidades, que geram novas "estruturas de sentimento", para dizer como R. Williams (1979), no início quase intraduzíveis literariamente, mas que aos poucos encontram modos expressivos adequados. Dessa maneira, sobretudo quando termina a

\footnotetext{
10 "Cabem aqui algumas palavras sobre o emprego apropriado deste conceito [...] cuja principal função é correlacionar a emergência de novos traços formais na vida cultural com a emergência de um novo tipo de vida social e de uma nova ordem econômica - chamada, frequente e eufemisticamente, de modernização, sociedade pós-industrial ou sociedade de consumo, sociedade dos mídia ou do espetáculo, ou capitalismo multinacional” (Jameson, 1985, p. 17).
} 
ditadura, acentuam-se as interações entre aspectos globais, identidades regionais e locais, questões de gênero e raça, desafiando conceitos estanques e formalizando-se esteticamente, mas adequando-se também com frequência ao gosto de um mercado já internacionalizado.

\section{Tempos modernos}

É no interior desse quadro, portanto, que acredito terem ocorrido mudanças de fato significativas para a literatura, pois a consolidação da indústria cultural conseguiu estabelecer parâmetros e paradigmas para as décadas subsequentes, já então direcionando a produção para diferentes "nichos de mercado", tanto no que se refere aos temas quanto aos resultados formais, os quais, desde então, passaram a sofrer, como nunca antes, o impacto das mais diferentes soluções abrigadas sob a "estética do espetáculo", principalmente as visuais, que se expandem celeremente.

Ora, a literatura sempre manteve estreito vínculo com a visualidade, devido ao seu diálogo histórico com a pintura, a fotografia e o cinema, por exemplo, e sempre esteve, também, ligada a mecanismos de compra e venda. Mas agora as coordenadas do mercado, cuja linguagem explícita é a imagética, impõem-se como parâmetro quase unidimensional; parafraseando Debord, acima citado, o espetáculo, que domina tudo, é, na verdade, o mercado, em tal grau de acumulação que se transformou em imagem. Pode-se dizer, então, que sua estética é a imagética, a da reprodução do existente, para que ele perdure e se acumule sempre mais, predominantemente em termos quantitativos e adequados à ideologia do consumo.

Assim, temas e soluções literárias "novas" encontradas ou recuperadas nos anos do regime, tanto como expressão individual, no corpo a corpo com a censura, quanto traduzindo as influências vindas de fora, de algum modo já atuantes, passam a ser imitadas e reduplicadas depois, sendo rapidamente diluídas as fontes que lhes deram origem. As aspas em "novas" a meu ver são necessárias, pois a ausência delas só se justificaria se o termo traduzisse uma transformação radical, a substituição de algo por outra coisa completamente diferente, e não se referisse a modificações, alterações, retomadas, apropriações ou outros termos equivalentes, estes sim adequados para definir a maior parte dessa produção. 
Refiro-me em especial às principais matrizes, representadas - apenas como exemplo -, por João Antônio, Dalton Trevisan e Rubem Fonseca, consolidadas durante os anos da ditadura, tematizando a exclusão social e a violência urbana, seja com "microficções", como Trevisan, ou com brutalismo direto, como Fonseca; daí deriva uma enxurrada de autores levantados pelo mercado e pelos efeitos visuais da fatura, como Marçal Aquino, Marcelino Freire, Marcelo Mirisola e outros, pertencentes ao que se chamou de "Geração 90". ${ }^{11}$ Refiro-me também a Ignácio de Loyola Brandão, cuja herança modernista que ressoa nas ousadias formais de Zero (1975), como a apropriação do rumor da rua e a atomização do discurso, vem sendo mimetizada por Luiz Ruffato e Lourenço Mutarelli; à própria Clarice Lispector, de quem se veem sonâncias e dissonâncias nas inúmeras vozes femininas que enchem as prateleiras das livrarias, os blogs e as redes sociais; a Graciliano Ramos, que, retirado da década de 1930, ainda hoje alimenta o neorregionalismo de Milton Hatoum e Ronaldo Correia de Brito.

Não utilizo aqui categorias valorativas para esses autores, e nem é o caso, mas destaco que se inserem em um processo construído sempre de continuidades, mais que de rupturas, como se pode verificar num exame mais acurado de seus textos. Cada uma dessas matrizes citadas estabelece-se como continuidade no interior da série da literatura de ficção, sendo possível estabelecer sua linhagem desde que começou seu processo de formação; e é inegável que cada momento histórico a ela soma novos aspectos temáticos e formais, como influência interna e/ou externa. Lembrem-se as vanguardas do início do século passado instaurando a fragmentação na linearidade discursiva e a desconstrução do enredo; a sondagem psicológica insuflando uma nova capacidade de penetração ao realismo; a crise da representação inspirando a desconfiança na suficiência do real; a incorporação consciente de outras linguagens, como a fotografia, o cinema, a propaganda, isso tudo para ficar apenas nas matrizes do século XX.

Chamo matrizes as formações literárias duráveis, que permanecem ao longo do processo histórico, às quais se acrescentam ou das quais se retiram, sem afetar seu núcleo, aspectos circunstanciais, devidos a cada momento, sendo que tais aspectos têm maior ou menor densidade ou

11 Denominação criada pelo mercado para agrupar escritores considerados “jovens”, que se expressam em temas e soluções formais diversificadas, embora tenha sido a representação da violência que garantiu maior visibilidade. 
força na dependência dos fatores externos em jogo. ${ }^{12} \mathrm{O}$ núcleo dessas matrizes duráveis, na literatura brasileira em prosa, parece ser o realismo, ${ }^{13}$ que persiste nas suas expressões urbanas e regionais, introspectivas ou não, para usar a terminologia consagrada.

Naquilo que me interessa, pode-se dizer que o período da ditadura militar teve força e densidade suficientes para, por meio de seu aparato político e jurídico autoritário e totalizador, constituir aspectos circunstanciais nacionais combinados com a conjuntura internacional de desenvolvimento da cultura, os quais, incidindo sobre a literatura, possibilitaram o ressurgimento de matrizes temáticas e expressivas modificadas, que foram sendo retomadas, revisitadas e adaptadas nas décadas subsequentes, num processo contínuo de continuidades e rupturas, mais ou menos intensas. Dessa forma, como sublinhei, o adjetivo "novo" dificilmente pode ser aplicado a qualquer aspecto; o que se pode chamar de novo, todavia, é a amplitude e intensidade do modo mercantil de produzir literatura - modo que não é novo em si,$-{ }^{14}$ algo antes desconhecido no panorama nacional, consolidado então, a que, nos dias de hoje, acrescenta-se a visualidade e a volatilidade intensas propiciadas pela tecnologia eletrônica.

Nesse sentido, importa historicizar e periodizar também o termo contemporâneo, no que se refere à cultura e à literatura, utilizado, a meu ver, com excessiva fluidez nos textos críticos em geral, sem o devido agendamento histórico. Com base na definição de matriz, aqui colocada, proponho entendê-lo como um conceito de periodização, que se inicia, no Brasil, com o regime militar e seu "projeto de modernização", acima exposto, propiciando um notável processo de mudança nos modos de produção cultural, artística e literária, que passaram a ser industriais e mercantis, incidindo direta e indiretamente sobre as matrizes literárias preexistentes. Obviamente não existe uma relação determinista nessa incidência, mas uma tensão inescapável entre ela e as subjetividades

\footnotetext{
${ }^{12}$ É clara aqui minha adesão aos conceitos de dominante, residual e emergente, de Raymond Williams.

${ }^{13}$ Também de Raymond Williams é o conceito de realismo que utilizo: "Nenhum elemento, seja a sociedade ou o indivíduo, é prioritário. A sociedade não é um pano-de-fundo contra o qual as relações pessoais são estudadas, nem os indivíduos são meras ilustrações de aspectos dos modos de vida. Cada aspecto da vida pessoal é radicalmente afetado pela qualidade da vida geral, mas a vida geral, no seu âmago, é totalmente vista em termos pessoais.” (Williams, 2001, p. 304). Essa utilização fica mais clara em meu texto "Realismo: postura e método" (Pellegrini, 2007).
}

${ }^{14}$ A história do livro e da leitura pode comprovar isso. 
autorais, por sua vez também tensamente inscritas nessas formações densas e complexas.

Em artigo publicado no caderno "Mais!" do jornal Folha de S. Paulo, em 2000, fazendo um balanço da literatura dos anos 1990, Flora Süssekind constata já uma "geminação entre o econômico e o cultural" muito distante dos aspectos de resistência e solidariedade interna vividos durante a ditadura. Escrevendo durante o crescimento da política neoliberal do governo Fernando Henrique Cardoso, ela percebe, quinze anos depois do fim da ditadura, o sucesso daquele projeto cultural, influenciando as configurações do que denomino matrizes literárias.

Se, de 1964 a 1984, durante a ditadura, os traços eram a resistência cultural, a solidariedade interna antiditadura [...] passa-se a viver, mesmo entre os setores mais críticos da sociedade, sob uma despolitização generalizada e diretamente proporcional à disseminação de uma financeirização todopoderosa - a invocação recorrente às leis do mercado acoplada à experiência neoliberal (Süssekind, 2000, p. 8).

Essa financeirização - que é, na verdade, a velha mercantilização elevada ao seu patamar mais alto - consegue desmontar os parâmetros de conteúdo e forma, para remontá-los em novas combinações, mais adequadas aos valores que se impõem e às subjetividades que se formam nesse quadro. Cria-se assim uma aparente instabilidade, resultado das tensões dos elementos em jogo, que quase se afigura como crise, mas na verdade é apenas uma adequação posterior às coordenadas definidas no momento da ditadura, com seus constrangimentos claros e objetivos. Literariamente traduzida pela critica em geral como aquilo que se costuma chamar pluralidade ou multiplicidade, seja de temas ou de soluções expressivas, essa "crise" articula-se como a apresentação de uma variedade prismática que de fato é a retomada de antigas matrizes, apenas recompostas de outra maneira, ou da mesma maneira com outras cores e matizes. Devido à complexidade do problema aí posto - que não pretendo resolver aqui -, pode-se dizer, com Fábio A. Durão, que a multiplicidade, ${ }^{15}$ também assumida como categoria crítico-analítica, é "um lugar-comum [que se] adequa ao espírito do nosso tempo: ela tem ares democráticos". Isso porque:

${ }^{15}$ Acrescento pluralidade. 
A multiplicidade funciona assim como um óleo lubrificante, não só para a maquinaria universitária, mas para a indústria da cultura como um todo. O paradoxo não deixa de ser interessante: o pressuposto da multiplicidade é aquilo que faz com que todos os textos [...] assemelhem-se, com que todos se tornem iguais em sua suposta diferença (Durão, 2013).

\section{Tempos pós-modernos}

É nesse sentido que talvez não seja equivocado afirmar que a prosa brasileira pós-ditadura continua "em trânsito", pelo fato de retomar sempre, pluralizando-as ou multiplicizando-as, no sentido apontado, matrizes que a acompanharam desde a sua formação, como o realismo, incorporando alterações e efeitos conjunturais. O problema é que, muitas vezes, tenta-se conciliar o inconciliável: o sentido de tradição que impulsionou a retomada delas, com todo seu lastro simbólico e ideológico, e, por meio da readequação de uma série de elaborações formais ainda relacionadas às inovações modernistas (elisões, cortes, diluições, fragmentações, etc.), nunca abandonadas, naquele momento francamente contrárias à reificação da arte, ensaiar uma aparente resistência à mercantilização, que passou a dar as cartas desde então.

Trocando em miúdos, parece-me lícito afirmar que, terminado o regime militar, em 1985, além de já estabelecer uma confortável intimidade com o mercado, revigorado pelos incentivos de todos os tipos, como se viu, a ficção abandona a anterior disposição de resistência, em grande parte comprometida com um ideário político de esquerda, registrado nos seus testemunhos, confissões, romances-reportagens etc., de forte cunho realista, cujos expoentes foram Fernando Gabeira, Renato Tapajós, Aguinaldo Silva, Ivan Ângelo e outros.

Não que tenham desaparecido, durante esse tempo, processos de formalização mais sofisticados, de cunho introspectivo, como os sempre citados Quatro olhos, de Renato Pompeu, e Armadilha para Lamartine, de Carlos Süssekind, considerados "novos" então. Acentuam-se outras soluções temáticas de recorte urbano, evidentemente ditadas não apenas pelo mercado mas por coordenadas sociais e políticas que se relacionam, inclusive, a impulsos internacionais: a voz das minorias (mulheres, negros, homossexuais), o universo das drogas, da violência e da sexualidade, num tom geral que expressa o "desencanto" do final do século com as esperanças goradas de um país que se sonhara mais justo. 
É preciso frisar que o abandono do ímpeto da resistência é apenas relativo, pois ela ainda pulsa, só que mais atomizada, calcada em micropolíticas individuais, bem distantes da utopia coletiva de antes; assinale-se que aí se representa a afirmação daquelas vozes "outras" abafadas, que conseguem aos poucos um espaço de locução, inclusive como decorrência da própria organização desses segmentos sociais enquanto movimento político emergente "pós-abertura"; não se trata mais de resistir à ditadura militar, mas a uma hierarquia ancestral em que predomina o discurso branco, masculino e cristão; são, portanto, outros sujeitos que se expressam, em dicções marcadas por uma diferente perspectiva, pois muitas vezes vêm de outro lugar social. Mas aí também se instala o mercado editorial, que avidamente descobre nessas temáticas fatias de mercado promissoras. ${ }^{16}$

Como exemplo, destaquem-se o gradativo alteamento e modulações das vozes femininas, que estimulam interpretações críticas de interesse, como constata a revista Leia livros, já em 1990:

Foi nos libertários anos 60 que se começou a levantar a poeira dos séculos e a se cunhar expressões como "olhar feminino". Nos anos 80 , como tudo indica, a questão não se esgotou, embora tenha adquirido outros contornos. [...] A escrita feminina obedeceria a uma outra lógica, onde o sujeito narrativo não é íntegro, pleno, e por vezes se projeta no objeto, "coisificando a palavra" (Luzvarghi, 1990, p. 28).

O mesmo acontece com a escrita dos homossexuais, registrada como ascendente e digna de nota, analisada no número seguinte da mesma revista: "Se existe uma característica homossexual na literatura, ela apareceria numa maneira ambígua de se expressar. [...] O homossexual vive num estado constante de ambiguidade" (Rosenbaum, 1990, p. 15).

Não se trata aqui de aprofundar tais questões, mas de destacar que essa literatura, também de caráter múltiplo, estrutura-se tensamente com base em matrizes já atuantes no Modernismo e suas marcas mais relevantes, em geral, são a distensão do limite entre realidade e imaginação, a recusa ao realismo puro, documental, sem escapar,

\footnotetext{
${ }^{16}$ Cresce aos poucos o espaço ocupado individualmente, com autoras como Ana Miranda, Zulmira Ribeiro Tavares, Marilene Felinto e outras. Já nos anos 2000 explodem várias coletâneas de contos, organizadas por Luiz Ruffato: 25 mulheres que estão fazendo a nova literatura brasileira (2004) e Mais 30 mulheres que estão fazendo a nova literatura brasileira, ambas da editora Record, em que os títulos falam por si.
} 
porém, de suas refrações: a subversão proposital dos parâmetros tradicionais de narração; a utilização de ambivalências e sugestões, pautando a representação em contradições, subvertendo padrões tradicionais de entendimento e explorando níveis de consciência e de linguagem. Tais características também frequentaram a ficção produzida durante a ditadura, mas com menor incidência, como indiquei; o que se percebe, mais ou menos a partir dos anos 1990, ou da "década do desencanto", é a centralidade da expressão subjetiva, o que já é um sintoma de época.

Assumida como centro do mundo, a subjetividade, como princípio estruturante, manifesta-se em uma espécie de esgarçamento da realidade circundante, desde que o foco de interesse passa a ser o próprio eu e aquilo que nele se reflete, pois é a medida de todas as coisas; surgem e se afirmam como padrão personagens sintonizadas com transformações nos conceitos e escalas de valor; na verdade, são revivescências das antigas matrizes introspectivas formalizadas no Modernismo, que se consolidaram sobretudo com Lygia Fagundes Telles e Clarice Lispector - não por acaso mulheres -, que agora se reconstroem em desencanto e niilismo, com sensível atenuação do sentido crítico de antes. Fredric Jameson (1985) refere-se a esse tipo de narrativas como pastiches - descontando-se a acidez do termo -, frutos da visão esquizofrênica provocada por um mundo em que o sujeito se reduplica na imagem cindida de si mesmo.

Leyla Perrone-Moisés (2012), todavia, identifica nessa mesma matriz uma espécie de resistência possível, na medida em que percebe em alguns autores e em seus recursos de fatura um traço muito forte de desconfiança, uma espécie de revivescência da "era da suspeita", definida por Natalie Sarraute, pois, segundo ela, desconfia-se do eu, do narrador, das histórias como representação e da literatura como instituição, além de se rejeitar o excesso de informação, de consumo e de imagens. São os que ela chama de "escritores exigentes", uma minoria, entre os quais alinha Nuno Ramos, Evando Nascimento, Julián Fuks e Alberto Martins. E acrescenta:

E para quem escrevem esses escritores exigentes? Certamente para um número restrito de leitores, tão inteligentes e refinados quanto eles [...]. Eles sabem que não entrarão nas listas dos mais vendidos, como aqueles que satisfazem os anseios de entretenimento dos 
leitores de romances, esses mesmos tão poucos num país iletrado como o nosso (Perrone-Moisés, 2012, p. 5).

Seja como pastiche ou exigência, mas contrastando com a sutileza das subjetividades, emerge da matriz fonsequeana, que já era a tradução moderna ${ }^{17}$ da violência constitutiva da sociedade brasileira, desde a sua fundação, o realismo bruto dos guetos e das favelas. É outro tema que se aprofunda, expressando as ambíguas relações entre a modernização brasileira e a violência, acentuadas durante a ditadura e depois. Violência e degradação misturam-se à presença maciça da cultura popular urbana, pervadindo as vidas de personagens sem presente e sem futuro. Esses temas aparecem vazados nas mais diversas maneiras de encarar a linguagem como representação, mas a principal está centrada no pacto realista, quase o registro in natura da ocorrência quotidiana. Importa aí o significante unívoco e a veracidade do sujeito narrador, trabalhando com matrizes da antiga denúncia social, também facilmente apropriável pela indústria, devido à aproximação expressiva com os discursos e recursos da mídia, do cinema, da propaganda. ${ }^{18}$ É a estética do espetáculo dando-se a ver como documento "real", embora represente um aporte social significativo de subjetividades gestadas em meio à pobreza e à exclusão das periferias, como mais uma das vozes antes inaudíveis a conclamar coesões identitárias. A esse entrelaçamento dos códigos, o literário e o imagético, aos poucos, acrescenta-se mais um, o da internet, que explode definitivamente as fronteiras entre o "literário" e o "não literário", na medida em que tudo se resume à necessidade de comunicação rápida e facilmente inteligível entre todos, aliando recursos de todos os suportes. Literatura, no início do novo século, mais que mercadoria, passa a ser mercadoria digitalmente comunicável.

Publicidade, diversidade, pluralidade, multiplicidade, visibilidade. Seja qual for o sentido que se dê a esses termos, é inegável que, a despeito de si mesmos, tornaram-se centrais para o exercício da crítica hoje, pois são o âmago do próprio ato criativo, como característica da própria linguagem enquanto resultado dos processos de subjetivação contemporânea,

\footnotetext{
${ }^{17}$ Utilizo "moderno" como um conceito de periodização, relacionando-o ao pós-moderno posterior.

${ }^{18}$ Foi Cidade de Deus (1997), de Paulo Lins, o primeiro a explorar esses aspectos. Seguem-se Estação Carandiru (1999), de Dráuzio Varela, e Capão Pecado (2000), de Ferréz, todos de grande êxito editorial, a ponto de gerar adaptações cinematográficas e seriados de televisão e (re)criar uma denominação própria, "literatura marginal”, já com ampla bibliografia crítica. Desenvolvi esse tema em "Vozes da violência na cultura brasileira” (Pellegrini, 2008).
} 
submetida aos estímulos da "condição pós-moderna". São termos que correspondem a traços temáticos e formais facilmente detectáveis em qualquer narrativa e cunhados para qualificar modelos textuais passíveis de aplicação e reaplicação de antigas matrizes, cujas modificações mais agudas deram-se durante a ditadura militar, com a gradativa consolidação da indústria cultural e do mercado literário, de acordo com o projeto do regime. Desde então, ao longo do caminho, de mistura com alguma "exigência" - minoritária, mas que garante esperança - foram sendo incorporadas soluções de aplicação pouco problemática, bem adequadas a contratos com grandes editoras e ao mercado externo, bem como à rarefação perceptiva e conceitual do leitorado interno, domesticado pela própria indústria e pela indigência educacional do país, que essa indústria, hoje poderosa, com o empenho da ditadura, ajudou a sedimentar. Relíquias de uma casa já velha de cinquenta anos.

\section{Referências}

CACASO (1981). A democracia passa pela discussão do pluralismo cultural. Folha de S. Paulo, São Paulo, Folhetim Brasil, p. 6-9, 5 abr.

CALABRE, Lia (Org.) (2005). Políticas culturais: diálogo indispensável. Rio de Janeiro: Casa de Rui Barbosa.

CARPEAUX, Otto M. (1973). Arte e sobrevivência. Opinião, Rio de Janeiro, n. 9, p. 6,1 a 8 jan.

COHN, Gabriel (1984). A concepção oficial da política cultural nos anos 70. In: MICELLI, Sergio (org.). Estado e cultura no Brasil. São Paulo: Difel.

DEBORD, Guy (1997). A sociedade do espetáculo. Rio de Janeiro: Contraponto.

DURÃO, Fábio Akcelrud (2013). Crítica da multiplicidade. Cult, São Paulo, n. 182, ago. Disponível em: <http://revistacult.uol.com.br/home/2013/09/criticada-multiplicidade>. Acesso em: 10 mar. 2013.

ESCREVER vale a pena (1990). Leia Livros, n. 138, p. 2, abr.

FERNANDES, Millôr (1983). Os intelectuais e a política. Folha de S. Paulo, São Paulo, Folhetim, p. 7-8, 23 out.

FERNANDES, Natália A. Morato (2013). A política cultural à época da ditadura militar. Contemporânea: revista de sociologia da UFSCar, São Carlos, v. 3, n. 1, p. 173-192. 
GALVÃO, Walnice Nogueira (1999). Musa sob assédio. In: Desconversa. São Paulo: Companhia das Letras.

HOLANDA, Heloísa B.; GONÇALVES, Marcos A. (1980). Política e literatura: a ficção da realidade brasileira - anos 70. Rio de Janeiro: Europa.

JABOR, Arnaldo (1973). Dez anos de cinema nacional. Opinião, Rio de Janeiro, n. 32 , p. 6-8, 11 a 18 jun.

JAMESON, Fredric (1985). Pós-modernidade e sociedade de consumo. Novos estudos CEBRAP, n. 12, p. 16-26.

LUSVARGHI, Luiza (1990). Feminino plural. Leia, n. 135, p. 28-29, jan.

MICELLI, Sérgio (1984a). Teoria e prática da política cultural oficial no Brasil. Revista de administração de empresas, Rio de Janeiro, v. 24, n. 1, p. 27-31.

(1984b). O processo de construção institucional na área cultural federal (anos 70). In: MICELLI, Sergio (org.). Estado e cultura no Brasil. São Paulo: Difel.

ORTIZ, Renato (1988). A moderna tradição brasileira: Cultura brasileira e indústria cultural. São Paulo: Brasiliense.

PELLEGRINI, Tânia (1996). Gavetas vazias: Ficção e política nos anos 70. Campinas: Mercado de Letras; São Carlos: Ed. UFSCar.

(1999). A imagem e a letra: aspectos da ficção brasileira contemporânea. São Paulo: Mercado de Letras; Fapesp. 135-155. (2007). Realismo: postura e método. Letras de hoje, Porto Alegre, n. 42, p.

(2008). Despropósitos: estudos de ficção brasileira contemporânea. São Paulo: Annablume; Fapesp.

PERRONE-MOISÉS, Leyla (2012). A literatura exigente. Folha de S. Paulo, São Paulo, Ilustríssima, p. 4-5, 25 mar.

RAMOS, Fernão P. (1986). Uma forma histórica de cinema alternativa e seus dilemas na atualidade. In: Vinte anos de resistência: Alternativas da cultura no regime militar. Rio de Janeiro: Espaço e Tempo.

REIMÃO, Sandra (2011). Repressão e resistência: censura a livros na ditadura militar. São Paulo: EDUSP, Fapesp.

RIDENTI, Marcelo (2010). Brasilidade revolucionária. São Paulo: Editora UNESP. ROSENBAUM, Yudith (1990). Filhos do terceiro sexo. Leia, n. 136, p. 28-29, fev. 
SCHWARZ, Roberto (1978). Cultura e política, 1964-69. In: O pai de família e outros ensaios. Rio de Janeiro: Paz e Terra.

(1981). A democracia passa pela discussão do pluralismo cultural. Folha de S. Paulo, São Paulo, Folhetim, p. 6-9, 5 abr.

SÜSSEKIND, Flora (1985). Literatura e vida literária: polêmicas, diários \& retratos. Rio de Janeiro: Jorge Zahar.

(2000). Escalas e ventríloquos. Folha de S. Paulo, São Paulo, Caderno Mais!, p. 8, 23 jul.

TELLES, Lygia Fagundes (1981). O editor, na versão do autor. Folha de S. Paulo, São Paulo, Folhetim, p. 8, 22 fev.

VIANA, Zelito (1973). Dez anos de cinema nacional. Opinião, Rio de Janeiro, n. 32, p. 6-8, 11 a 18 jun.

WILLIAMS, Raymond (1979). Marxismo e literatura. Rio de Janeiro: J. Zahar. (2001). The long revolution. Canada: Broadview Press.

Recebido em dezembro de 2013.

Aprovado em janeiro de 2014.

\section{resumolabstract}

\section{Relíquias da casa velha: literatura e ditadura militar, 50 anos depois}

Tânia Pellegrini

Este ensaio, amparado em consulta a jornais e revistas de várias décadas, além de revisitar parte da produção crítica sobre o tema e de retomar minhas próprias pesquisas anteriores, procura relacionar as ações específicas do regime militar para o campo da cultura com a efetiva consolidação da indústria cultural brasileira. O pressuposto é que essa consolidação engendrou, de forma tensionada, modificações significativas nas matrizes preexistentes na nossa ficção, sobretudo temáticas, que foram traduzindo o mal-estar e a perplexidade geradas naqueles anos difíceis, bem como suas derivações até os dias de hoje.

Palavras-chave: ditadura militar, indústria cultural, matrizes literárias.

\section{Relics of the old house: literature and military dictatorship, $\mathbf{5 0}$ years after} Tânia Pellegrini

This essay tries to relate specific actions of the military regime in the field of culture to the effective consolidation of a cultural industry in Brazil. It is based 
on a more or less alleatory search in newspapers and magazines of the period. It also revisits the critical literature about the subject and retakes my own previous researches. The assumption is that the cultural industry consolidation has produced in a tensioned way, significant modifications in the preexistent matrixes of Brazilian fiction, mainly in its themes, which translated the mallaise and perplexity of those difficult years, as well as their derivations to this day.

Keywords: military dictatorship, cultural industry, literary matrices. 